\title{
The Status of the Social in Creativity Studies and the Pitfalls of Dichotomic Thinking*
}

\author{
Vlad Petre Glăveanu \\ Aalborg University, Denmark \\ E-mail address: vlad@hum.aau.dk
}

ARTICLE INFO

\section{Keywords: \\ Creativity \\ Social \\ Potential \\ Achievement \\ Divergent thinking \\ Perspectives \\ Time}

\section{A B STRACT}

Article history:

Received 4 February 2015

Received in revised form 10 February 2015

Accepted 14 February 2015

ISSN: 2354-0036

DOI: 10.1515/ctra-2015-0016
Creativity studies seem to be a stronghold for individualbased psychological theories. The reasons for this are numerous and complex and, among them, we can identify certain limited or counter-productive ways of conceptualising the social. In this reply to comments I address both the status of the social in creativity studies and the dichotomies that follow from adopting an external view of society and culture. Among them, the separation between creative potential and achievement is particularly problematic, as it constructs a reified, static, and individual notion of potential, reflected in the measurement of divergent thinking. I propose, towards the end, a perspectival model of creativity that radically socialises divergent thinking by placing the social at the core rather than the periphery of creative production. Finally, I suggest that including time into our theory and research holds the key to overcoming many of the false dichotomies that underline creativity studies, at least in psychology. A thoroughly social perspective on creativity might seem like a daring or foolish endeavour but it is, in my view, also the most promising.

In this second reply to comments I will focus on two problematic notions in creativity theory and research. The first one, the 'social', is problematic because of its unclear and often questioned status, the second one, 'potential', because of its popularity and rarely problematised place in our field. The set of commentaries included in this second issue relate, in one way or another, to these topics. I would like to express, once more, my deep gratitude to the authors for contributing to this on-going dialogue and to the editors for making it possible.

\section{The troublesome concept}

If there are two things we probably all agree with, they are: 1) the fact that the social world is important for creativity (although this importance varies from one commentator 
to the next) and 2) that it is generally hard to theorise and to investigate empirically (Hui, 2015; Min Tang, 2015; Hennessey, 2015). Social aspects are too multifaceted, systemic and dynamic to be easily operationalised in research. Min Tang (2015) offers a very good list of reasons why the systems approach is "an easier-said-than-done method" (p. 80). Among them:

1. the difficulty of assessing creativity in a truly systemic manner;

2. the lack of sound instruments to capture interactions between components;

3. the bandwidth-fidelity dilemma (number of variables - in-depth exploration);

4. poor communication between psychologists and other specialists;

5. the trade-off between maintaining complexity and simplifying it for research.

These are all valid points but we need to go even deeper, historically, to understand the current situation that applies not only to creativity research but psychology as a whole. At the root of many of the problems above we find the continuous effort of our discipline, over the last century and a half, to mimic the natural sciences (Watson, 1913; Knopf, 1924). Wundt's separation between experimental and social psychology (Völkerpsychologie) marked not only the birth of a new science but also its subsequent path. The most famous followers of Wundt took the experimental model initially applied to psychophysiological functions alone and gradually extended it to 'higher mental functions', including social phenomena, despite Wundt's own reservations (for more details see Farr, 1983). Thus began a long history of individualising the social and desocialising the individual, even within the rather vigorous field of social psychology (Graumann, 1986) and, arguably, much research in social cognition today continues this legacy.

Why do social psychologists and their creativity colleagues follow this path? The reasons, both then and now, are numerous. Scientifically, the rise of positivistic conceptions grounded in measurement and 'parsimonious models' (see Runco, 2015) prompts us to look for the simplest (causal) explanations. Unfortunately, a careful study of humans as social beings frustrates this goal by adding too much complexity, too much 'noise' that is better left out if we are to obtain 'clean' theories with predictive value. Pragmatically, engaging with the social at different levels and focusing on relations and interactions goes against our current tradition of conducting 'proper' experiments. This is because, in order to cut reality into measurable variables, we first need to isolate factors that are, normally, inter-dependent and, second, we have to focus on static outcomes (translated into numbers) rather than processes and transformations. Conceptually, we are also often trapped by an old way of thinking about the social as opposed to the individual, destroying personal agency, and leading to pathological forms of action (we can recall here 
old conceptions of 'crowd behaviour' and the pervasive association between clinical and social psychology). This fallacy is particularly damaging for the field of creativity, which strives to understand how individuals go beyond conformity and compliance with social 'pressures'. Politically, there is much more prestige to be gained from playing the scientific game of using complicated statistics and the latest in brain research technology than risk being confused with a social scientist or, worse, a scholar from the humanities. From funding agencies to academic boards, this orientation is imposed on new graduates in psychology and makes it hard for them to be professionally successful outside of the mainstream (Hennessey, 2015; Persson, 2015; Moran, 2015). Everything that falls outside the orthodoxy of the field (and these boundaries also cut off the transpersonal; Kharkhurin, 2015), are risky ventures in professional terms.

Paradoxically however, a psychology of creativity built around the lone individual fails to be either scientific or useful. A 'parsimonious theory of creativity' (Runco, 2015) that downplays the social aspects strives to represent 'good science' but ends up promoting dangerous forms of reductionism (Montuori \& Purser, 1997). Carefully crafted experiments that focus only on intra-psychological dimensions or operationalise social aspects only as independent variables illuminate, at best, only parts of the phenomenon or, in the worst cases, misconstrue it altogether. Psychometric measures, the trademark of creativity research, perfect this individualisation effort by operating with a definition of creativity as a mental property. Meanwhile, at a practical level, the outcomes of cognitive and personality research into creativity can never be applied directly to concrete situations precisely because they construct and study abstract, universal individuals. Real life however doesn't come packed so nicely and demands close attention to social relations and cultural context. Ironically, an individualistic psychology of creativity ends up doing away with its own research topic - the person - replacing it with numbers, arrows and boxes (see also Valsiner, 1986). In order to fully understand and appreciate the individual in creative expression we need to start from the social.

\section{Conceptualising the social}

The real question is: what does it mean to start from the social? What does the category of social comprise? A variety of ideas come to mind: social relations, values, norms, practices, family contexts, roles, culture, institutions, communication, legitimation, interaction, groups, collaboration, and so on. It is certainly difficult to take all of the above (and more) into account within a single theory and this is how we have today a number of different conceptions of the social within creativity studies, briefly summarised as follows: 
1. Gatekeeper. One of the most prominent accounts of the social, the gatekeeper model, is specific for historical and systemic research (Simonton, 2003; Csikszentmihalyi, 1998). It basically operates with a sociological, institutional reading of society and culture that considers them both organised systems conditioning individual creativity. Conversely, creative expression depends on social recognition and validation by gatekeepers within the social field (such as reviewers, museum curators, award committees, etc.). Thus, creativity is defined in terms of social agreement about what is new and valuable and it cannot exist outside of it. While the great benefit of this approach is that it makes us sensitive to the social and historical construction of what we consider creative, the gatekeeper view of the social applies mainly to significant creative achievements and 'high culture' domains such the arts, sciences, technology, etc. Arguably, in everyday life situations we could still identify people holding a 'gatekeeper' function but such mundane instances of creativity are largely outside the scope of this branch of research;

2. Consensus. Building on the above, and addressing the limitation mentioned last, is the consensus model of the social that 'democratises' the use of social agreement. The famous Consensual Assessment Technique (Hennessey \& Amabile, 1999; Hennessey, 2015) makes it possible to study little-c creative outputs (like drawings, poems, etc.) with the help of expert judges in specific cultural contexts. Here consensus is taken, at the same time, as a mark of the social constitution of creativity and the best sign that something is 'really' creative (in those cases in which consensus is high). However, what this approach to the social ignores is the fundamental role of divergence and difference within society. While people using this methodology are happy to find agreement and take it as an indication that creativity is 'there', plain to see, they both make the social more uniform than it is and privilege one social position (experts) over others;

3. Cluster. One apparent solution against excessive homogeneity is represented by what can be called cluster models. Made popular by the influential research of Hofstede (2001) on cultural dimensions, this conception theorises the social as a patterned system of values and behaviours. Among the various dimensions proposed, the individualism - collectivism one is a classic and was imported by creativity research in the study of differences between East and West (see for example Zha, Walczyk, Griffith-Ross, Tobacyk \& Walczyk, 2006). One of the obvious problems with this approach however is that, despite trying to differentiate the social world, it ends up reifying and dichotomising cultural differences. This is how we are 
left with a view of what creativity is supposed to be in a certain cultural space (usually defined at the level of nations) but one that doesn't apply to concrete individuals and relations which, of course, transcend simple categories;

4. Box. Not everyone is concerned with the higher level of (national) culture. Very often the social influences researchers focus on in their studies have to do with a more immediate social environment (family, peers and collaborators, etc.). Inclusive models of creativity like the multivariate approach (Lubart, 2003) place the environment alongside other dimensions such as cognitive, conative, and affective. While incorporating the social component is already a step forward, the fact that it becomes a 'box' among others, typically an 'external' one, reinforces the distinction between creator and world. Moreover, it leaves unquestioned the social constitution of intrapsychological functions such as cognition, motivation, affect, etc. Even group creativity models, which supposedly focus on interaction, actually often operate with different boxes (or circles) to depict the individual and shared areas of knowledge and skill (Nijstad \& Paulus, 2003). In the end, making room for the social as a separate, self-contained box in our models is an insufficient theoretical move since it ignores temporal and developmental aspects (see last section);

5. Shopping list. Boxes are not only static but also tend to lack precision in terms of their contents. In fact, very often a discussion of social factors in creativity research takes the form of an enumeration unavoidably ending with 'etcetera' or 'so on'. Creativity scholars are not solely to blame for this tendency. An early omnibus definition of culture by Edward Tylor (1871) refers to "that complex whole which includes knowledge, belief, art, morals, law, custom and any other capabilities and habits acquired by man as a member of society" (p. 1). It is not only the lack of structure or organisation but also this 'other' category that is troubling. The social environment is indeed complex and multifaceted but simply creating a 'shopping list' of terms to cover most (yet not all) its aspects is a way of acknowledging but not really unpacking the meaning of society or culture;

6. Onion. At last, if one is keen to organise the elements inside the social 'box', an easy solution is offered by Bronfenbrenner's (1979) ecological systems model, depicting an onion-like image in which the individual, at the centre, is surrounded by concentric circles: the microsystem, the mesosystem, the exosystem, and the macrosystem. Similarly, the level dimension in Batey's framework (cited by Hui, 2015) includes the individual, the team, the organisation, and the culture. While these attempts to systematise the social world in relation to one's topic of interest - 
in our case creativity - can be a good starting point, they suffer as well from several limitations. First of all, their perspective is hierarchical, going from lower to higher levels of complexity, without always specifying the dynamic interactions between levels. Second, despite being embedded within larger levels, these models give researchers the impression they can cut a 'slice' of the social world and focus on it with little or no interest for what happens elsewhere.

Gatekeepers, consensus, clusters, boxes, shopping lists, and onion layers - these are only some of the obvious ways in which the question of the social is answered in creativity research (and beyond). Each comes with its own merits and limitations but, at least in my view, none of them is truly satisfactory because they all have one thing in common: they assume that the social exists somewhere, 'out there', surrounding individual creators. The social is always external, the self separated from others, even if in close interaction with them (see Marková, 2003, for a compelling critique of this epistemological position). In other words, the social can shape the dynamic of creativity but is not a constitutive element of it (a key argument for Runco, 2015, addressed in more detail as follows). This position, endorsed by positivism, builds on the Cartesian legacy of separating mind from matter, person from environment, self from society (Jovchelovitch, 2007).

But it is not the only perspective available. Sociocultural scholarship, including dialogism (Bakhtin, 1981), positioning theory (Harré \& van Langenhove, 1998), social representations (Moscovici, 1984), activity theory (Engeström, 1987), symbolic interactionism (Mead, 1934), semiotics (Valsiner, 2014), and developmental research (Vygotsky, 1978), make great efforts to overcome the basic Cartesian split. However, with a few notable exceptions (including several commentators to the lead article like Seana Moran, Alfonso Montuori, or Lene Tanggaard), these types of scholarship have rarely been consistently applied to creativity research. And yet, the externality of the social in the case of creativity - and the human mind in general - is not only a misleading but also a potentially harmful position. Its consequences are the proliferation of dichotomies, particularly that between potential and achievement, something I continue to discuss next.

\section{The pitfalls of dichotomic thinking}

A couple of years ago I wrote about relational thinking in the psychology of creativity (Glăveanu, 2012) as a way of transcending oppositional categories. What thinking relationally about the social in creativity does is help us challenge strict separations between 'inner' and 'outer', self and other, mind and world. It not only puts the two side by side, but considers how subjective experience is co-constructed in the dynamic exchanges between person and environment. Citko's (2015) commentary, from the perspective 
of an artist, tries to highlight some of these subjective aspects of creating while, at the same time, placing them beyond the positivist logic of measurement. While I am also doubtful about the 'flat' ontology this logic pursues, I would stress the need to be critical, as well, of romanticised views of creators and their activity. The difference between doing science and doing art is yet another fundamental dichotomy that needs to be questioned (see Dewey, 1934) in constructing a relational account of what it means to create.

It is often assumed that, if art aims to complexify reality, science often proceeds by simplifying it. And yet, not all simplifications are necessarily simplistic. The parsimonious theory of creativity Runco (2015) advocates for in his commentary certainly has strong foundations, both historical and methodological. It strives to eliminate unnecessary or less necessary elements and focus our attention on what is essential for the creative process. I am not against such clarifications. However, where Runco's and my position radically diverge is precisely in the treatment of the social element. His declared aim is "to put the social view of creativity in its place" (p. 22) and this place is, at best, secondary. He does not deny that the social environment plays a part in creativity but theorises this role in terms of 'social influences' and 'social ramifications', in other words, what comes both before and after the creative act itself. He writes:

"Simplifying some, there are (a) influences on creativity, (b) a mechanism which is required for the creativity, and (c) possible results of the creativity. In the last category you have social judgment, attributions, and the 'reconstructions by others' that Glăveanu describes in his featured article. Only (b) is, however, required for creativity. Both (a) and (c) should be recognized as things that either precede or result from creativity, but since they are not vital to creativity, they should be kept out of a definition of creativity" (Runco, 2015, p. 25).

What we can notice here, first of all, is a Gatekeeper conception of the social (see the previous section), a reading of it strictly in terms of recognition, fame, and social validation. In this sense, society might influence creators and incorporate (or not) their outcomes but it is not, itself, part of the 'mechanism' of creativity. This 'mechanism' remains individual, psychological, not social. Such an external view of the social leads Runco to further conclusions:

"Additionally, creativity need not lead to implementation. It need not be judged or labeled creative. If it is socially recognized, there may be a consensus about it, which can be a good thing. This could even be indicative of inter-judge reliability" (Runco, 2015, p. 23).

The classic distinction between idea generation and idea implementation, key in to- 
day's discussions about creativity and innovation (West, 2002), is grounded in an external conception of the social. If creativity denotes how we get ideas, and if this process takes place in the mind, then surely what happens to these ideas afterwards, once 'externalised', must be a different kind of process altogether, involving exploration, testing, and social consensus. And, Runco continues, since this consensus (inter-judge reliability) is highly contextual and changing (not really reliable...), then a social definition of creativity can never be "objective nor scientifically acceptable" (p. 24). How are we to construct a truly scientific account of something that "depends on who is perceiving or describing it" (Moran, 2015, p. 65)?

It is far easier to just assume that "creativity does not require a tangible product, nor an audience" (Runco, 2015, p. 28) and focus our attention on psychological mechanisms. But of course studying these mechanisms as they unfold, particularly in real-life instances of creativity, is problematic because these instances stubbornly bring back products and audiences... This is why it is often more comfortable for psychologists, following 'parsimonious models', to focus on creative potential - mental operations (like divergent thinking) assumed to matter for real-life creativity and even to be predictive of it. I am not going to review here the long debate about whether creativity tests of potential actually have real predictive value (for more more detailed discussions readers can consult Zeng, Proctor \& Salvendy, 2011; Plucker \& Runco, 1998). It is not the methodological apparatus that concerns me most but the (often implicit) underlying dichotomies behind theories of creative potential. A general summary looks as follows:

TABLE 1.

\section{Popular dichotomies in creativity theory and research}

\begin{tabular}{|c|c|}
\hline Creative ideation & Idea implementation \\
\hline Divergent thinking & Social evaluation \\
\hline Potential & Achievement \\
\hline Psychological & Social \\
\hline Self / creator & Other / audience \\
\hline
\end{tabular}

What I have listed in Table 1 are the main topics for creativity and innovation researchers, presented in dichotomic pairs. On the one hand, on the left, we find creative ideation processes, often studied as divergent thinking (but not only, we can include here associative, lateral thinking, etc.), expressive of what is supposed to be the creative potential 
of the individual or, rather, of his or her psychological makeup. On the other hand, on the right, we find the implementation of creative ideas, their social evaluation, leading to concrete creative achievements that necessarily relate to different audiences in the social arena. Now, to be sure, many creativity scholars might be interested in studying both creative potential and creative achievement; moreover, they might very well study creative potential in order to understand or predict achievement (a concern for reputable scholars such as Torrance, referred to also by Runco). But, unfortunately for the psychology of creativity, researchers often stop at the level of potential... Because creative potential is located typically 'inside' the individual, his/her thinking processes in particular, it makes sense for psychology to be concerned with it! The social as a troublesome concept (see first section) can be best approached by other disciplines like sociology and anthropology. To differentiate itself, and claim scientific status, psychology has developed a complex methodological apparatus to study creative potential as its privileged area of expertise.

The problem is that traditional understandings and measurements of potential in the psychology of creativity are skewed, as they draw on dichotomic rather than relational thinking. A number of contradictions should give pause to the current industry of testing for 'creative potential':

1. Tests of creative potential impose a false distinction between potential and achievement by separating the testing situation from 'real-world' practices. Creative achievement is what people do in naturalistic settings, what is celebrated by others as creative, what depends on social consensus. But isn't the testing situation itself part of the real world? Aren't ideas put on paper examples of creativity within the social situation constructed by the social practice of testing? Isn't scoring a form of social validation? The illusion cultivated in psychology that its theories and methods belong to the realm of science and this realm is somehow independent from everyday life (Tanggaard, 2015) is at work here. To reach a conclusion about what the person could accomplish (potentially) we certainly need to ask the person to do something practical (like a divergent thinking task). But, strangely, this doing and its outcomes are not yet achievement because for this we need to produce something of true social value. The Gatekeeper, institutional, 'high culture' model of the social prevents us from seeing creativity testing as an activity in itself and, as with any activity, asking questions about how useful is it for it to be organised the way it is;

2. A second basic problem is that, based on testing and numerical assessment, 
we end up studying creative potential as a static reality. Indeed, to trust any assessment of creative potential we must first assume it is a rather stable 'property' of the individual being tested. Of course creativity research has, by and large, abandoned today a highly reified and fixed understanding of potential as inscribed within the laws of heredity (Galton, 1874) and it does tend to test potential at different moments in time to observe its evolution (typically though not before half a year to a year). Potential remains, however, a 'thing' rather than a dynamic construction that depends, moment to moment, on the system of social relations the individual is a part of. This essentialist ontology goes hand in hand with the separation mentioned above between what is 'inside' and 'outside' the creative person;

3. Finally, potential is usually theorised and studied in psychology as an individual construct. We could talk or think about the potential of a certain social network or culture to foster creativity but this is generally considered outside the scope of psychologists. This radical individualisation is inscribed into the methods we use, particularly in individual forms of testing. Such a conceptualisation fails to realise that the potential for creativity exists at the interface between person and his/her socio-material world (something acknowledged much better in educational psychology in the study of 'aptitudes', for example; see Lohman \& Lakin, 2006). It is, in fact, a quality of the relation between them and, therefore, bears the mark of the constant transformations taking place within this relationship. This might be bad news for a methodological apparatus based on studying individuals alone. But it is good news for efforts to bridge creativity assessment and intervention (Tanggaard \& Glăveanu, 2014). If we consider creativity tests as practical and socially constituted activities, we have a better chance of evaluating creative potential while fostering it in contexts of interaction (between participant and researcher, multiple participants, etc.).

Of course the critique above is not new in the psychology of creativity. However, a small group of critical voices (particularly sharing a social or socio-cultural background) doesn't seem, until now, to be able to fundamentally shake the established practices of the majority. But the dilemmas this practice confronts us with don't go unnoticed even for its advocates:

"This raises the important question of how to study creative potential that has not yet been manifested in the form of any activity or product? In my opinion, this type of research will, sooner or later, inevitably encourage the individual being studied to demonstrate a variety of behaviours, that from the perspective of the researcher represent an indirect measure of the ability to create, but from the point of view of the respondent, 
will be forms of activities detached from everyday life. Consequently, we come full circle and receive, what we now call, a critique of the psychometric approach" (Gralewski, 2015, p. 51).

This feeling of being trapped in a loop Gralewski mentions, I argue, is a consequence of thinking in dichotomies. The strict separation between creative potential and creative achievement, and the way creative potential is conceptualised in psychology, are certainly problematic. They are also deeply related to the broader dichotomy between what is psychological and what is social in the creative process. Because self and other are kept distinct we are unable to see them, in fact, as inter-dependent and interchangeable positions. The creative self is audience to the creations of others and his/her own creations just as other people from the audience are creators in their own right (Glăveanu, 2011). Our understanding and measurement of divergent thinking, as prime examples of testing creative potential, would benefit most from these kinds of insights and ontological re-grounding.

\section{Socialising divergent thinking}

Before continuing I would like to dispel a potential accusation: that in the effort to bring the social to the fore I might be dismissing the individual and his/her psychology. As I have mentioned many times before, my position is anti-individualistic, not antiindividual. I am not denying the crucial role of the human mind in conceiving, shaping and carrying out creating activities, but I postulate the mind as social and distributed (Valsiner, 2014; Hutchins, 1995). Creative action is one of the best illustrations of this distribution of mind into the world (Glăveanu, 2014) as it both mobilises existing cultural artefacts and leads to the creation of new objects, processes, and relations. When it comes to divergent thinking, this means I am not refuting it as a component, perhaps a key component, in the dynamic of creativity. I also don't think trying to understand and assess this component is necessarily misleading. What I am lamenting are the purely cognitive, intrapsychological ways in which this concept has been both theorised and measured. We shouldn't, however, throw out the baby with the bathwater and note, together with Lubart and Caroff (2015), that quite some progress has been made in psychometrics in the last decades (see Karwowski, 2015). The EPoC instrument they refer to evaluates both divergent and convergent thinking and does so in a domain-specific manner. This is certainly an advancement and perhaps Lubart and Caroff are right to say that the big community which has today invested in using such tests is not necessarily "barking up the wrong tree" (p. 45). But is it imagining this tree to be different from what it actually is?

In an upcoming article (Glăveanu, forthcoming) I propose a perspectival model of crea- 
tive action that engages with the social and developmental theory of George Herbert Mead (1934) and more recent Neo-Meadian scholarship (Gillespie 2006a,b; Gillespie \& Martin, 2014). The basic premise of this model is that, when people generate new ideas as part of their on-going creative action, they do so by alternating between and integrating perspectives and these perspectives are fundamentally linked to social positions and practices. In other words, the cognitive processes involved in divergent thinking are intrinsically social as they both emerge out of social experience and reflect its polyphonic and dialogical character. This last feature is well documented in dialogism and dialogical self theory (Hermans, 2001), another strand of literature that strongly advocates for a social reformulation of seemingly individual, intra-psychological processes.

Consider, for example, the well-known item asking people to generate as many ideas as possible about what they could do with a brick. We can expect here respondents to mention building things, or using bricks to support objects, to cook on, as bookshelf ends, to break a window, to attack someone, etc. In purely cognitive terms, these are divergent ideas, drawing on existing knowledge that is stored in one's memory within semantic networks, selectively activated and combined during the task (see for example the associative memory model of creativity; Brown \& Paulus, 2002). Little attention is paid to how these ideas have been acquired, why they are organised in certain ways, and what they tell us about the social architecture of the human mind. This is because traditional accounts of creative thinking don't consider our engagement in creative tasks as directly related to our participation in society. In contrast, a truly social account highlights the fact that, as part of socialisation processes, we acquire an understanding of different social positions around us, such as parent and child, sister and brother, doctor and patient, buyer and seller, etc. This is a sign of decentration in early development (i.e., realising there are other people with different needs and views of the world), of children becoming capable to 'escape' first-person perspectives that tie them to the here and now of perception and action. Understanding that other perspectives exist and enacting them, as well as bringing them to bear on one's own position, is an enormous achievement for the development of self, consciousness, reflexivity, and, of course, creativity. In symbolic play and, later on, in games, children learn to 'become', in turn, and in a very embodied manner, other people and to adopt their roles within given situations (consider, for instance, the game of hide and seek; Gillespie, 2006b).

Different social perspectives enrich our understanding of the world. Moreover, the repositioning they entail comes to constitute a mechanism deeply embedded in how we participate in society as creative social actors. To return to the brick example, con- 
structing, cooking or harming are not simply ideas but perspectives that come out of a long personal and cultural history of experiencing, physically and/or symbolically, different social positions: that of builders, cooks and fighters. Respondents might not identify them as such during the creative task but this only suggests the relative automatisation of perspective-taking processes. Its social dynamic becomes more obvious in everyday contexts in which using a brick or any other artefact necessarily has to take into account a complex set of expectations, norms, and human relations.

The perspectival model briefly outlined above is only one way in which we can socialise divergent thinking and, at the same time, place the social at the core of the 'creativity mechanism' (Runco, 2015), not exclusively before and after creativity takes place. This conceptual move however requires us to go beyond classic ways of theorising the social as external (embodied by gatekeepers or social consensus; see first section) and 'introduce' it within the mind and within the creative act. Socialising creativity in this way challenges current understandings and measures of divergent thinking and creative potential more generally. Their tasks can be kept and enriched, but their use and interpretation should change. Mental categories, concepts, and knowledge that were previously understood as residing inside the head are now spread within networks of relations and interactions. Individual testing can leave room for collaborative activities. Numerical scores are not to quantify potential as an enigmatic, disembodied property of isolated individuals. If used, they should give us another measure of the richness of our life worlds as social and cultural beings.

\section{Final reflections on creativity (theory) in the making}

For those readers who have patiently followed my line of argument up to this point, I want to end with a few practical reflections. Some of the ideas above might have resonated with their own questions about creativity or personal experiences of creating and, at the same time, many new questions probably emerged in the process. Overcoming dichotomies is no easy task since, in addition to being social, our minds are also dialogical and thus inclined to think in terms of opposites (Marková, 2003). What matters is how these oppositions are constructed. My call for relational thinking (Glăveanu, 2012), leading to social/relational theories of creativity, encourages us to think about categories dynamically, as inter-dependent and embedded in one another. But I will be the first to admit that this is easier said than done. And yet, when in doubt, there is quite a simple and effective solution at hand: consider phenomena (like creativity) in their temporal dimension.

Including time (historical, ontogenetic, microgenetic) into the equation of creativity 
is what several commentators have pointed to as well (among them, Ai-Girl, 2015; Moran, 2015; Wagoner, 2015). Why is it such an effective strategy? Simply because, using a longitudinal and developmental perspective, we cannot but observe how polar categories shift and change, merge and transform. Creative ideation and achievement, for example, are continuous with each other, and what people think about and do at time $x$ opens up a new sphere of potential achievements at time $x+1$. Moreover, social consensus, that seems external to the creator at one moment, becomes internalised by him/her later on and feeds into on-going creative action. This is how, taking the perspective of different audiences, particularly users, critics and gatekeepers (broadly defined), is so crucial for both nurturing one's own creative process and having one's creative outcomes recognised within society. Social consensus, just like difference and divergence, doesn't exist only 'outside' the person, it becomes part and parcel of a complex and polyphonic society of the mind (Hermans, 2002) or, I would specify, of the creative mind. Time doesn't only help construct a more sophisticated (even if not always parsimonious) theory of creativity, but can also greatly help us put it to good use. A dynamic, developmental view of creative potential directs our attention away from questions of 'how great is this potential?' towards 'what can be done to foster it in interaction?'. The gap between assessment and intervention disappears if we use divergent thinking tasks as part of on-going activities and socialise their use and interpretation.

All this might sound quite optimistic, I admit, but whoever engages with creativity from a socio-cultural perspective can only be an optimist at heart. I perceived the same enthusiasm for this approach in the comments of many colleagues, as well as in their useful suggestions (for example Hoff and Carlsson's, 2015, thoughtful expansion of the social paradigm); this dialogue and the new creativity journal it is published in reinforce my hopefulness. The social view continues to stand out as a unique, if not bizarre approach to creativity, a field of study long attached to the individual. But this might very well be taken as a sign of its own creativity.

\section{REFERENCES}

Bakhtin, M. M. (1981). The dialogic imagination: Four essays. Ed. Michael Holquist. Trans. Caryl Emerson and Michael Holquist. Austin and London: University of Texas Press.

Bronfenbrenner, U. (1979). The ecology of human development: Experiments by nature and design. Cambridge, MA: Harvard University Press.

Brown, V. R., \& Paulus, P. B. (2002). Making group brainstorming more effective: Recommendations from an associative memory perspective. Current Directions in Psychological Science, 11, 208-212. 
Engeström, Y. (1987). Learning by expanding: An activity-theoretical approach to developmental research. Helsinki: Orienta-KonsultitOy.

Farr, R. M. (1983). Wilhelm Wundt (1832-1920) and the origins of psychology as an experimental and social science. British Journal of Social Psychology, 22, 4, 289-301.

Citko, K. (2015). "And what is a beautiful poem"? Reflections of a poet on Vlad Petre Glăveanu's 'The psychology of creativity: A critical reading'. Creativity. Theories - Research - Applications, 2, 1, 97-101; DOI: 10.1515/ctra-2015-0015.

Csikszentmihalyi, M. (1998). Creativity and genius: A systems perspective. In A. Steptoe (Ed.) Genius and the mind: Studies of creativity and temperament (pp. 39-66). Oxford: Oxford University Press.

Dewey, J. (1934). Art as experience. New York, NY: Penguin.

Galton, F. (1874). English men of science: Their nature and nurture. London: MacMillan.

Gillespie, A. (2006a). Becoming other: From social interaction to self-reflection. Greenwich, CT: Information Age Publishing.

Gillespie, A. (2006b). Games and the development of perspective taking. Human Development, 49, 87-92.

Gillespie, A., \& Martin, J. (2014). Position exchange theory: A socio-material basis for discursive and psychological positioning. New Ideas in Psychology, 32, 73-79.

Glăveanu, V. P. (2011). Creativity as cultural participation. Journal for the Theory of Social Behaviour, 41, 1, 48-67.

Glăveanu, V. P. (2012). From dichotomous to relational thinking in the psychology of creativity: A review of great debates. Creativity and Leisure: An intercultural and crossdisciplinary journal, 1, 2, 83-96.

Glăveanu, V. P. (forthcoming). Creativity as a sociocultural act. Journal of Creative Behavior.

Gralewski, J. (2015). The Psychology of Creativity: A Discussion Between Creative Potential and Its Realization. Creativity. Theories - Research - Applications, 2, 1, 49-55; DOI: $10.1515 /$ ctra-2015-0007.

Graumann, C. F. (1986). The individualization of the social and the desocialization of the individual: Floyd H. Allport's contribution to social psychology. In C. F. Graumann \& S. Moscovici (Eds.), Changing conceptions of crowd mind and behavior (pp. 97116). New York, NY: Springer-Verlag.

Harré, H. R., \& van Langenhove, L. (Eds.) (1998). Positioning theory. Oxford: Blackwell. Hennessey, B. A. (2015). Comment on "The Psychology of Creativity: A Critical Reading" by Vlad Petre Glăveanu. Creativity. Theories - Research - Applications, 2, 1, 3237; DOI: 10.1515/ctra-2015-0004. 
Hennessey, B. A., \& Amabile, T. M. (1999). Consensual assessment. In M. A. Runco \& S. R. Pritzker (Eds.), Encyclopedia of creativity, Vol. 1 (pp. 346-359). San Diego, CA: Academic Press.

Hermans, H. J. M. (2001). The Dialogical Self: Toward a theory of personal and cultural positioning. Culture Psychology, 7, 243-281.

Hermans, H. J. M. (2002). The dialogical self as a society of mind. Theory \& Psychology, 12(2), 147-160.

Hoff, E., \& Carlsson, I. (2015). She, You and They - More actors on the creativity research stage! Creativity. Theories - Research - Applications, 2, 1, 38-43; DOI: 10.1515/ctra-2015-0005.

Hofstede, G. (2001). Culture's consequences: Comparing values, behaviors, institutions and organizations across nations, 2nd ed. Thousand Oaks, CA: Sage.

Hui, A. N. N. (2015). Commentary on 'The psychology of creativity: A critical reading'. Creativity. Theories - Research - Applications, 2, 1, 56-63; DOI: 10.1515/ctra-2015-0008.

Hutchins, E. (1995). Cognition in the wild. Cambridge, MA: MIT Press.

Jovchelovitch, S. (2007). Knowledge in context: Representations, community and culture. London: Routledge.

Karwowski, M. (2015). Notes on Creative Potential and Its Measurement. Creativity. Theories - Research - Applications, 2, 1, 4-16; DOI: 10.1515/ctra-2015-0001.

Knopf, A. A. (1924). Principles of psychology. New York, NY: Kantor, J. R.

Kharkhurin, A. (2015). The Big Question in creativity research: The transcendental source of creativity. Creativity. Theories - Research - Applications, 2, 1, 90-96; DOI: 10.1515/ ctra-2015-0014.

Lohman, D. F., \& Lakin, J. (2006). Nonverbal test scores as one component of an identification system: Integrating ability, achievement, and teacher ratings. In J. VanTasselBaska (Ed.). Alternative assessments for identifying gifted and talented students. Austin, TX: Prufrock Press.

Lubart, T. (2003). Psychologie de la créativité. Paris: Armand Colin.

Lubart, T., \& Caroff, X. (2015). Has creativity research become a trivial pursuit? Creativity. Theories - Research - Applications, 2, 1, 44-48; DOI: 10.1515/ctra-2015-0006.

Marková, I. (2003). Dialogicality and social representations: The dynamics of mind. Cambridge: Cambridge University Press.

Mead, G. H. (1934). Mind, self and society from the standpoint of a social behaviorist. Chicago: University of Chicago Press. 
Min Tang, L. (2015). Revisiting the systems approach: Commentary on Glăveanu's paper "The Psychology of Creativity: A Critical Reading". Creativity. Theories - Research Applications, 2, 1, 79-84; DOI: 10.1515/ctra-2015-0012.

Montuori, A., \& Purser, R. (1997). Social creativity: The challenge of complexity. Translation of Le dimensioni sociali della creatività. Pluriverso, 1, 2, 78-88.

Moran, S. (2015). Creativity is a label for the aggregated, time-dependent, subjective judgments by creators and by adopters. Creativity. Theories - Research - Applications, 2, 1, 64-69; DOI: 10.1515/ctra-2015-0009.

Moscovici, S. (1984). The phenomenon of social representations. In R. Farr \& S. Moscovici (Eds.), Social representations (pp. 3-70). Cambridge: Cambridge University Press.

Nijstad, B., \& Paulus, P. (2003). Group creativity: Common themes and future directions. In P. Paulus \& B. Nijstad (Eds.), Group creativity: Innovation through collaboration (pp. 326-339). New York, NY: Oxford University Press.

Persson, R. (2015). Erudite, insightful and immensely important: A commentary on V. P. Glăveanu's critical article 'The psychology of creativity - a critical reading'. Creativity. Theories - Research - Applications, 2, 1, 17-20; DOI: 10.1515/ctra-2015-0002.

Plucker, J. A., \& Runco, M. A. (1998). The death of creativity measurement has been greatly exaggerated: Current issues, recent advances, and future directions in creativity assessment. Roeper Review, 21, 1, 36-39.

Runco, M. A. (2015). A Commentary on the social perspective on creativity. Creativity. Theories - Research - Applications, 2, 1, 21-31; DOI: 10.1515/ctra-2015-0003.

Simonton, D. K. (2003). Creative cultures, nations, and civilizations: Strategies and results. In P. Paulus \& B. Nijstad (Eds.), Group creativity: Innovation through collaboration (pp. 304-325). New York, NY: Oxford University Press.

Tan, A.-G. (2015). Knowing creativity. Creativity. Theories - Research - Applications, 2, 1, 85-89; DOI: 10.1515/ctra-2015-0013.

Tanggaard, L. (2015). Reaching out for everyday life creativity. Creativity. Theories - Research - Applications, 2, 1, 75-78; DOI: 10.1515/ctra-2015-0011.

Tanggaard, L. \& Glăveanu, V. P. (2014). Creativity assessment as intervention: The case of creative learning. Akademisk Kvarter/Academic Quarter, 9(1), 18-30.

Tylor, E. B. (1871). Primitive culture: Researches into the development of mythology, philosophy, religion, art and custom, 1. London: Murray.

Valsiner, J. (Ed.) (1986). The individual subject and scientific psychology. New York, NY: Plenum.

Valsiner, J. (2014). An invitation to cultural psychology. New Delhi: Sage. 
Vygotsky, L. S. (1978). Mind in society: The development of higher psychological processes. Edited by M. Cole, V. John-Steiner, S. Scribner \& E. Souberman. Cambridge, MA: Harvard University Press.

Wagoner, B. (2015). From crisis to creativity: Towards a psychology of creating. Creativity. Theories - Research - Applications, 2, 1, 70-74; DOI: 10.1515/ctra-2015-0010.

Watson, J. B. (1913). Psychology as the behaviorist views it. Psychological Review, 20, 2,158-177.

West, M. A. (2002). Sparkling fountains or stagnant ponds: An integrative model of creativity and innovation implementation in work groups. Applied psychology: An international review, 51, 3, 355-424.

Zeng, L., Proctor, R. W., \& Salvendy, G. (2011). Can traditional divergent thinking tests be trusted in measuring and predicting real-world creativity? Creativity Research Journal, 23, 1, 24-37.

Zha, P., Walczyk, J. J., Griffith-Ross, D. A., Tobacyk, J. J., \& Walczyk, D. F. (2006). The impact of culture and individualism-collectivism on the creative potential and achievement of American and Chinese adults. Creativity Research Journal, 18, 3, 355-366.

Corresponding author at: Vlad Petre Glăveanu, Department of Psychology and Communication, Aalborg University, Kroghstræde St. 3 , 9220 Aalborg, Denmark E-mail: vlad@hum.aau.dk 